\title{
Type I Chiari Malformation Presenting in an Adult
}

\author{
Orlando Garner, Saranya Rajasekar, Ana Ramirez, Alfredo lardino
}

Internal Medicine, Texas Tech University Health Science Center at the Permian Basin, Odessa, Texas, USA

\section{Correspondence to} Dr Alfredo lardino, alfredo.iardino@ttuhsc.edu

OG and $\mathrm{Al}$ contributed equally.

Accepted 31 May 2018

\section{DESCRIPTION}

Type I Chiari malformations (CMs) is an acquired or congenital disorder characterised by the presence of the cerebellar tonsils at $5 \mathrm{~mm}$ or below of the spinal canal, which can result in abnormal cerebrospinal fluid flow and produce headaches, syrinx or hydrocephalus. CMs are still considered an uncommon disease with a prevalence in the USA of less than $1 \% .^{12}$ We present a 44 -year-old man with no medical history who presented to the emergency department complaining of nausea, vomiting, vertigo and a 2-day history of headaches exacerbated with Valsalva manoeuvres. He was initially admitted with a working diagnosis of ischaemic stroke and underwent a CT scan of the brain, which was unremarkable. Further work-up with brain MRI disclosed incidental cerebellar herniation $6.5 \mathrm{~mm}$ below the foramen magnum (figure 1) and no abnormalities in spinal canal MRIs. The patient was treated symptomatically with oral acetaminophen $500 \mathrm{mg}$ three times a day as needed, with improvement in symptoms, and was discharged home with an appointment with neurology for follow-up MRI and outpatient physical and occupational therapy. CMs seem to be more prevalent in the female population. Patients most commonly manifest with headaches and paraesthesia, sometimes accompanied by nausea, dysphagia, dysphonia, clonus, muscle atrophy and cerebellar symptoms, but not always.

When seeing patients with vague complaints, there should always be present in our differentials the common and more uncommon causes, and as in this case we should try to stick with diagnostic studies and clinical rationale that will help us dissipate

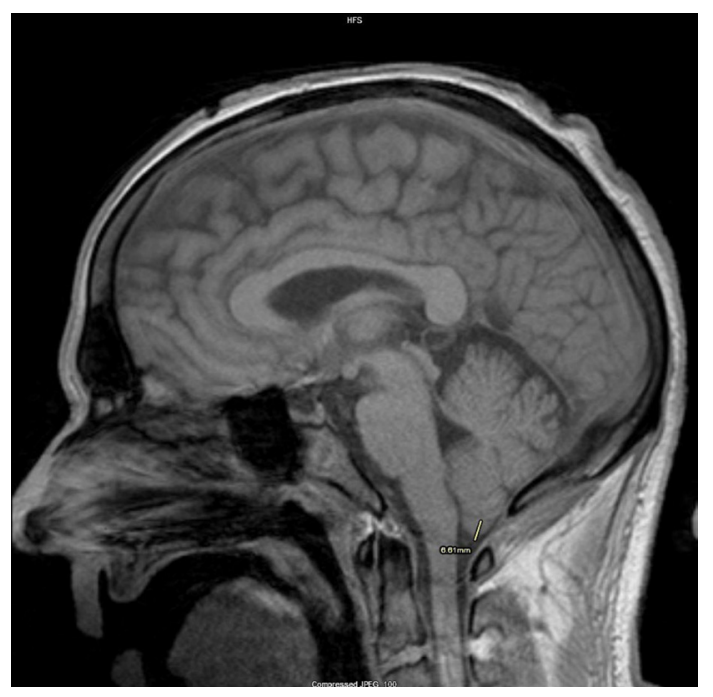

Figure 1 Sagittal view of MRI of the brain showing a $6.5 \mathrm{~mm}$ herniation of the cerebellar tonsils through the foramen magnum.

\section{Learning points}

- Careful clinical examination along with MRI allows us to differentiate between stroke and other less common neurological disorders such as type 1 Chiari malformations (CMs). Usually, stroke has symptoms that will resolve when the patient suffers a transient ischaemic attack or will persist if the patient has a complete stroke per se; additionally, these aforementioned entities will show hyperintense signals on MRI and no herniation of the cerebellar tonsil alone. Having in mind these distinctions will help practitioners to establish a difference between differential diagnoses.

- CM is not progressive, and symptoms may remain static or improve with time. Patients who are asymptomatic are likely to remain asymptomatic. CMs are divided into four different categories (CM types I, II, III and IV) with different degrees of severity, being CM type I the less severe characterised by cerebellar herniation of $>5 \mathrm{~mm}$ (in our patient $6.5 \mathrm{~mm}$ exactly-which is considered mild herniation).

- The other types of CM are characterised by major severity of symptoms, like paralysis below the anatomical neurological defect like in CM type II, multiple focal neurological symptoms like in CM type III and even incompatibility with life as observed in CM type IV.

- Observation with repeat MRI every year is appropriate for asymptomatic and mildly symptomatic patients with CM type I. Although there are no set guidelines for surgical intervention, reported criteria for surgery include symptoms of brainstem compression, syringomyelia, cough-associated headaches detrimental to quality of life, myelopathy, objective abnormal neurological findings and hydrocephalus, which in reality are very rare in CM type I and are more commonly seen in CM types II-III.

- The importance of the presented image lies in the fact that even if the working diagnosis on admission was ischaemic stroke, the fact that his complaints were so unspecific moved us to have more uncommon aetiologies for his symptoms into consideration, which helped in the later systematic review of the images telling a very subtle abnormality that gave us our final diagnosis.

options in order to achieve a final diagnosis and make good for our patients. Systematic review of MRI images in an organised fashion helped us make the diagnosis of CMs for which treatment has not been 
defined. Observation is advised in asymptomatic patients even with significant tonsillar herniation and surgical decompression can be performed in patients with severe symptoms. ${ }^{3}$

Twitter @Alfredolardinos

Acknowledgements Dr. George Rodenko for his reading and second opinion on MRI Report

Contributors OG: writing of manuscript, editing of images. SR: proof-reading of manuscript. AR: proof-reading of manuscript. Al: final approval of manuscript. OG and Al had the same contribution.

Funding The authors have not declared a specific grant for this research from any funding agency in the public, commercial or not-for-profit sectors.

Competing interests None declared.
Patient consent Obtained.

Provenance and peer review Not commissioned; externally peer reviewed.

(c) BMJ Publishing Group Ltd (unless otherwise stated in the text of the article) 2018. All rights reserved. No commercial use is permitted unless otherwise expressly granted.

\section{REFERENCES}

1 Doberstein CA, Torabi R, Klinge PM. Current concepts in the pathogenesis, diagnosis, and management of type I chiari malformations. R / Med J 2017;100:47-9.

2 Kahn EN, Muraszko KM, Maher CO. Prevalence of chiari I malformation and syringomyelia. Neurosurg Clin NAm 2015;26:501-7.

3 Langridge B, Phillips E, Choi D. Chiari malformation type 1: a systematic review of natural history and conservative management. World Neurosurg 2017;104:213-9.

Copyright 2018 BMJ Publishing Group. All rights reserved. For permission to reuse any of this content visit http://group.bmj.com/group/rights-licensing/permissions.

BMJ Case Report Fellows may re-use this article for personal use and teaching without any further permission.

Become a Fellow of BMJ Case Reports today and you can:

- Submit as many cases as you like

- Enjoy fast sympathetic peer review and rapid publication of accepted articles

- Access all the published articles

- Re-use any of the published material for personal use and teaching without further permission

For information on Institutional Fellowships contact consortiasales@bmjgroup.com

Visit casereports.bmj.com for more articles like this and to become a Fellow 